\title{
An inquiry on social issues - Part 1
}

\author{
Harshad Dave, India
}

\begin{abstract}
The readers who have studied the history of mankind and path of evolution of human society on this planet Earth will have better understanding of my saying in this article. I have presented my personal views and conclusions based on my contemplation on various social issues of our present society. I agree, there are innumerable social issues in our society and some of them varies with time and place also. There can never be a society without an issue. The issues are the foundation of flow of various processes and activities in the human society. However, at a glance, if we count on our fingers regarding the most sensitive and gruesome issues generally influencing major part of living world today, they are climatic and environmental issue, terrorism, drugs addiction, human trafficking, corruption, destruction of natural wealth, over growth in human population, health problem, child llabor and helpless sex workers and many other issues. We shall address these all social issues as "social issues" onwards to this article.
\end{abstract}

Keywords: social issue, preconditions, surplus population, socio-economic formation.

JEL Classification: A13, A14, B21, F43, F50, I24, O12, P16, P26, P48, Z13.

DOI: $10.21272 /$ bel.1(2).78-88.2017.

(C) The Author, 2017. This article is published with open access at ARMG Publishing.

\section{Introduction}

I specifically point out to the readers that I neither have suggested any remedy of the issues nor I have contemplated to search for the remedy in this article. I confess, whenever I think about remedy to short out the issues, I realized it is not so easy; rather it is "a mission impossible". However, history has taught us that any problem that is impossible to solve today, finds its way tomorrow with a beautiful remedy. So, I request to the readers that while they go through this article they should not anticipate that the author will suggest or recommend some remedy to come out from the social issues. I believe, if intellectual bank of our society grasps the realistic constitution of the social issues and if it recognizes motivating parameters behind them more practically, some remedy might also be surfaced out on time line in future. However, it is utmost necessary to recognize the real parameters and motivating forces that create and provide foundation to the above social issues. I have tried the same. I agree, the presented views might have errors and omissions. I welcome the young generations to work on them and correct the same.

I strongly believe that if we have clarity of root source of such social issues, we might be able to discover some remedies that, perhaps, might not fully cure us from the consequences emerged from them and presently we face, but it might lead us near to a cure. I directly and flatly narrate my views point wise hereunder.

Prime causes of the social issues:

I believe that following are the prime causes responsible for the present social issues as discussed above.

1. Presence of surplus population.

2. Sentiments of parents.

3. Ardent desire to satisfy ambitious wants and possibility of its realization.

4. Social system and human weaknesses.

5. Difference between two socio economic formations.

6. Rights and freedom without competency.

7. Some biological characteristics of human being and weaknesses in social system.

8. Let us discuss on the above causes.

\section{Presence of surplus population}

If we analyze wild life system, we learn that nature has created all provisions to curb the population strength of every living creature (animal, bird, insects, micro organism and others). It remains within a domain between two limits. The population strength generally floats between the two limits (maximum and minimum population strength). It might occasionally cross the limits for a temporary period but again it returns within 
the limits only. This is true for all living creatures in natural wild life system everywhere on this planet earth. The maintaining of the population strength within the two limits is realized by a process of destruction of the proportionate population of respective specie against addition through new born in wild life system. This destructed part of population is treated as a surplus population. The process of surplus population destruction in wild life is a part of wild life system and it is well established by way of evolution in natural system.

Do we ever have thought for any provision or process that ensures to dispose of surplus human population inside our social system? Perhaps, with some logical reasons, we always remain abstained from discussing the above issue. Let us glance on it.

It is a long but known story how man distinguished himself from other living creatures though it took a million or more years. Man established human society separating from prevalent wild life system. There are innumerable distinguishing points of difference between wild life system and human social system. However, adhering to our subject matter under discussion, I should point out that man separated from wild life system but could not find out a remedy "How to curb human population growth within the two limits in the society?" The path of development of human society from an ape to the present advance society is very long. However, scientists have discovered many facts to trace the path that might be considered reasonably reliable. If we study the path analytically, we might learn that every progressive advance in the status of human society presents innumerable changes, developments, transformations and movements compare to that of past status. However, one of the uniform developments might apparently be noticed, particularly during last two centuries and it is uncontrollable human population growth.

If we sharply disintegrate the phrase of words "development of human society", we shall learn that - efforts to retain survival with the help of discoveries and inventions and producing life supporting provisions for the same - occupies a major part of the process to whom we say "development of human society". Close your eyes and think on the words transportation, communication, conveyance, infrastructures, production system, raw materials, energy sources and other like words. If we try to work out magnitude of their role to support the survival of present human population on earth, we shall realize, as if they are meant for that only. There might be percentage wise very thin role being played by them for the purposes other than рориlation survival support. However, it is indisputable that they support the survival of population like a life line.

It is not fair to say "Man established human society". Rather it is better way to explain it as "Some of the abilities of man offered him an opportunity to survive or to make his living with ways and means other than and departing from that of established in the evolved natural wild life system. The process of making living with the help of such means compelled men to live together and it turned into human society." However, the span of departure was always within an acceptable limit. This acceptable limit was getting determined by the magnitude of distinguishing abilities man could successfully apply on natural resources. As application of distinguishing abilities grew more, the span of departure from natural wild life also got augmented. It became a process of development of human society. This process of social development led to a human society completely out of wild life system.

The subject span of departure from natural wild life brought many consequential changes. However, we shall discuss only one change that is concerned most to our subject matter of present discussion. The application of enhanced ability of man with the help of achievements through discoveries and inventions slowly evolved with such a social system that facilitated man to enjoy substantial immunities from natural adverse challenges to him.

Man is also a living creature in nature. There must be a specific limit of human population strength on our earth as warranted by law of nature. This might vary as per time and place. However, process of surplus population destruction must be applicable to human society also. Unfortunately, the above mentioned achievements offered man an extensive immunity from the population destruction process that prevails and was evolved in natural wild life. At the same time man failed to introduce any alternate process or system to replace a man made system to control population growth or to destruct surplus population in the society.

Why man could not establish a system to replace the prevalent natural system to curb population strength within two limits has more than one reason. One prime reason is "natural emotions and sentiments of parents towards their kids" (discussed under point 2 further to this article). Second reason is, man tried to ex- 
pand the size of the domain (between the two limits) of population strength in human society by invading natural resources more vigorously with the help of inventions, discoveries and lastly it got projected into massive industrial development. Perhaps, man could not constitute an apparent surplus population destruction system in the human society due to his ethical perception, emotional link of parents with their kids and many other reasons. However, instead of constituting any systematic method to curb the population strength within the natural limits prevailed in past at the same place/area, man tried to manage survival of surplus population with the help of application of his enhanced abilities on natural resources.

The growth in population, making efforts to enhance exploitation of natural resources to manage provisions of survival, removing limitations and obstacles in the above efforts utilizing practical applicability of fresh inventions and discoveries, searching and managing new energy resources etc have become perpetual and incessant processes in human society. They prevailed in the human social system and network causing interdependency among various activities in the society. Any effective change in the above processing invariably returns with a wave of disturbance and that wave propagates through the social network causing predictable and unpredictable consequences in the human society.

It is a fact that, generally, magnitude of population growth always remains higher than the magnitude of augmented provisions that could be practically realized through the application of enhanced abilities of men to facilitate accommodation of surplus population. A human society, at any socio economic formation, always faced a substantial deficit between magnitude of practical population growth and possibility for its accommodation in the society as above. This deficit is nothing but a mass of population that is present in the society but surely going to be destructed as there is no possibility of their accommodation in the society. This mass is so homogeneously amalgamated in the total population of the society that one cannot locate and point out towards any person at any moment in the society to designate him/her as a surplus one. Unfortunately, human society does not have any systematic and recognized process to detect those (surplus people). We know, the wild life system did have such process.

The process of destruction of surplus population established by natural wild life is not effective on human social system as already discussed before. Our human society has not developed any such process apparently with one or more reasons, man rather tried to settle it by producing additional provisions of survival as discussed above. The power of application of natural laws are so fierce that any immunity acquired by any one against them remains valid only if the subject process, system and provisions developed by man are kept alive and effective. As soon as a departure and interruption in the above set up is appeared, we will be immediately treated by natural laws only irrespective of our advance social status with our suits, ties and hats.

Here above, we discussed and learned that an amalgamated part of surplus population is always present in a society and the society has neither a system (established process) to destruct that surplus mass nor the provisions to support their living. The society enjoys immunity from the application of natural process to destruct the surplus population as it is done in natural wild life system. Existence of the surplus population, either without any provisions of its survival or without any determined process of its destruction, is a breach of natural law. The presence of surplus population ultimately causes many consequential reflections in the social system. The summarized and integrated effect of above consequential reflections in the society ultimately causes stress and strain in the activities, dealing, interactions and process of compliance among different systems and institutions of the society, between individual members of the society as well as among all of them as and when events and occasions arises. The above subject dealings and activities are inevitable for maintaining the prevailing socio economic formation stable. We shall address them as stress and strain onwards to this article. Perpetual presence of this surplus population is one of the prime root causes of the social issues that we discussed in Preamble. Today, we all make every effort to find remedy to come out of them (the issues) but we are not successful (The above mentioned stress and strain will be addressed at many places onwards to this article).

\section{Sentiments of parents}

All living creatures have a tendency to protect and secure survival of their kids or next generation. The ways and means of protection might very and differ with the species of creature, place and time. It is an outcome of evolution processes since millions of years that the living kingdom has passed through on the earth. Limiting our talk to animals to adhere the subject matter in concern, we might observe that they are attached to their kids with their esteemed emotions and sentiments towards them. Maintaining survival in the natural 
wild life is challenging one to each and every animal. The infant age of any kid is the time where its survival might be ensured with the external help only.

The emotions and sentiments discussed above provided an environment where kids are nurtured by the parents till their (kids) systems get developed and become competent to accept the challenges by natural wild life system for survival. This help of nurturing is nothing but a substantial share in the resources and means of subsistence managed by their parents from outside systems (world). All the animals are only with natural abilities in wild life system. The natural wild life system is full of challenges and with a struggle for survival. No animal can afford, for a longer time, a share from the means of survival managed by it for its own survival, with the help of resources of its various abilities. Nature created a system to share the same with their growing kids, for a limited period, only to defend the continuity and functioning of the ecological cycle. Nature put necessary emotions and sentiments to ensure the nurture of the kids till they become competent to survive on their own. This was applicable to apes and primitive men also, but they maintained their survival nearly on their natural abilities only.

When man developed a human society, he did not remain exclusively with his natural abilities only. But, his natural abilities are substantially being supplemented by new discoveries and inventions. Remember that the man is still with the same emotions and sentiments for his kids because it is a characteristic constituted in his nature by God only as discussed before. But, the unfortunate part is that he is now with supplemented abilities with him and makes his living in a human social system instead of natural wild life system.

The supplemented abilities and evolved human social system provided man an opportunity to extend the period of nurturing of his kids as discussed above. It also facilitated to support his kids in various ways and means just to satisfy his own emotions and sentiments towards his kids irrespective of their (kids') competency and age. This could be realized only because he was making his living in evolved human social system different from wild life system as well as he had various abilities supported and supplemented by outcome of discoveries and inventions. Otherwise, natural wild life system had never facilitated any animal to afford any such help to its kids beyond the prescribed period and other than the scheduled help. The emotion and sentiments in men discussed above are also responsible parameters for the above discussed social issues in present human society.

\section{Ardent desire to satisfy ambitious wants and possibility of its realization}

Let me narrate some words here. The words are need, want, requirement, necessity, desire, wish, ambition, yearn, lust and many other such words that I might have missed to enlist here. The above words have a basic foundation and vital linkages with various characteristics of man on one side. On other side, one or more of them is responsible for inducing man to act upon. If we scrutinize them, we realize that there are some most essential and inevitable needs like water, food, resting and shelter etc. We say them critical and essential needs. There are hundred thousand needs and wants other than critical and essential needs. The inevitability of their satisfaction and their justification are debatable issues. However, generally a man would always like to satisfy them though they are not of essential nature. This is true for all the men baring some exceptional cases. However, a great difference of opinion prevails for the justification and inevitability of each of them.

If we study the system of wild life, we should agree that a living creature has hardly a chance to enjoy their needs, wants and requirements etc amounting other than the essential needs. All animals are with their natural abilities just sufficient to survive. Occasionally any of them might find an opportunity to satisfy and enjoy such need or want etc that is out of the list of essential needs, otherwise they do not have spare capacity of resources as well as required abilities with them to satisfy such wants. The evolved human social system, its lucrative productive power, the men with supplemented abilities and some inherent constitutional weaknesses of human society provide an environment to find such opportunities to men in abundance. There are fair possibilities in human society for a man to satisfy his unjustified wants and desires.

It is the most ridicule weakness of human social system where man finds opportunities to satisfy such wants and yearns that are not only out of the list of essential or reasonably justified needs but majority of the people of the society might unanimously confirm that such wants and yearns are unethical and severely harmful to the good functioning of social system. The provision of facility to satisfy such wants in the social system is one of the most influencing parameter responsible for the creation of above discussed social issues. 


\section{Flows in human society and weaknesses in characteristics of man}

When men evolved with a social system different than the natural wild life system, the progressive construction of social system and its development under the influence of many parameters resulted into a typical constitution of human social system. The constitution of human society neither remained completely different and independent from that of natural wild life system nor did it remain purely a wild life system. It has always remained (till today even) a homogeneous amalgamation of both the systems. If we say in other way, natural wild life system and human social system distinguished from each other progressively. As there are innumerable regulating and influencing parameters responsible for making the subject constitution with above said amalgamation and many of the parameters are of floating nature, the classically synchronized compliance and tuning among the various parameters are extremely difficult... rather impossible. The above discussed fact constituted a human society with some flows and weaknesses in the social system.

Let us discuss a most simple example. Suppose there is a group of men making living in jungle with a use of sharp wooden stick as a spear to kill a prey. The group is working jointly to make living. They are able to manage a prey or defend themselves in better and more effective ways with the help of wooden stick cut from a suitable branch of a tree, sharpened it and practiced to use it skilfully. Let us recognize it (living of this group) as one of the primitive socio economic formations.

This social status is very simple but there are some preconditions also to be fulfilled to maintain the status. These preconditions are untold and unwritten. There must be someone who should always hunt (search) in the jungle to select and collect the most suitable branches of trees that are convenient to handle and operate effectively as a spear for its purpose. The collected branches are to be trimmed suitably and its one end is to be scraped to make it sharply pointed. This exercise will provide a facility to replace the fresh wooden spear against any one that got damaged or lost, otherwise it was in use.

The process of preparing spare wooden spears as above is a precondition for the maintenance of status of socio economic formation in group living as mentioned above. If development in the above group living progressed and resulted into a living habitation using fishnet for fishing, arrow and bow to kill a prey and lassos to catch birds and small games, there are more preconditions to be complied depending upon the use of inventions and discoveries for making living. We shall address these untold and unwritten preconditions as "preconditions" during our discussion in this article. If people of an old society make their living on agriculture, animal husbandry, poultry farm, fishing etc, there are various requirements to ensure benefits from their use. This compelled man to constitute a system and functioning of the constituted system with innumerable preconditions that became inevitable to ensure the productivity of provisions of survival.

For example, no one should loot or thief others goods, there must be exchange with some untold and unwritten rules etc. These preconditions are inevitable for the uninterrupted and trouble free functioning of the social system that is at a step up socio economical formation compare to previous one. Ultimately, these all preconditions for the society become essential for the ultimate productivity of the society to manage existence of the population.

When we progressively departed from the wild life system, man might not know that performance and functioning of the social system is ensured till the preconditions get fulfilled. As soon as a departure or a breach in the subject preconditions takes place, perpetually looming influence of natural laws will immediately get activated. In the event of failure in compliance to the preconditions, they (natural laws) become effective on human society also. The people will be treated under wild life natural laws after the breach in the preconditions. The impact of the influence of the natural laws would be in proportion to the magnitude of the departure from the preconditions.

The empirical knowledge of the subject preconditions and experience of resultant up set (turmoil) due to breach of them, perhaps, taught men inevitability to introduce various rules, laws and precedents to be followed in the social system. A social system functions under the rules and precedents which are evolved to constitute the same society. The bitter test of departure from it taught man empirically to remain within the frame work of the untold and unwritten rules and precedents that are evolved with the society. This silent and inevitable demand of complying rules and precedents taught men to develop a social system to ensure the warranted compliance. The development of judicial system and police force, control of church and religion etc in human society render the same services. Otherwise, the social system might again come under 
effective influence of wild life laws immediately on departure of one or more subject preconditions in the same society.

The curiosity, observations and intellectual contemplation on them, reminiscence power and experience, intelligentsia etc resulted into knowledge, discoveries and inventions, dexterity etc. They provided man an ability to act upon natural resources with an overall boosted ability. Also, this ability was to be applied on natural resources available in surrounding world by the people living there. The application of new abilities warranted for more working hands. However, if it is successful, it ensured and produced additional provisions necessary for making living as well as supporting their survival.

As such, a requirement of additional working hands was inevitable to produce the additional provisions. A mass of population found an opportunity to survive even if they do not have enough competencies to survive in purely natural wild life system. Such people used to become a part of the working hands in the social system. This development was the initiation of establishing a society with some processes, activities and material handling of various kinds that had never found a recognition and a place in the society in past. We address such society as a society with an advance socio economic formation.

The stepping up in socio economic formation was ultimately going to lead us to a most advance society in future. However, every development and advancement added different types of preconditions for retaining the latest socio economic formation alive. If any breach in the preconditions is happened, the reflections and influence of natural laws will create an adverse push that will try to drag and suppress the prevailing social system to drive back to the previous socio economic formation. A pushing back to previous socio economic formation is nothing but warrant of destruction of a part of the population that could remain in existence only due to the benefit accrued from present (prevailing) socio economic formation.

Here, I narrate very few untold and unwritten preconditions that prevailed to constitute a human society; however, the narrated list of the preconditions is just a sample and not complete. The enlisted preconditions here bellow are just to introduce reader with the preconditions. There are innumerable preconditions in a society. The numerical strength of preconditions increases as the socio economic formation of the society advances.

a) There must be availability of additional working hands to work and act upon the natural or other resources to produce the provisions for the people in the society. Here, availability of manpower to work on material or natural resources, managing required quantity of material or natural resources, passing on the knowledge about necessary working on the material to fresh generation are the untold and unwritten preconditions for the survival of all the additional population strength.

b) There must be a reliable distribution of the produced provisions to satisfy the various needs of the working people as well as it maintains confidence in the system.

c) As the young new generation enters the social system, there should be an impartial scrutiny for division of llabor strictly based on test of required abilities and competence.

d) There must be someone or a system that regulates and controls the functioning of all the activities in the prevailed social system. He should rule the people for working in harmony that is demanded by the preconditions. Once upon a time the ruling body was a leader of a group, then after the body was a king, and now it is a government of elected people and rule of laws. The step from group leader to elected government is not a change taken for pleasure, comfort and freedom. It was an inevitable demand to retain the functioning of social systems, institutions and compliance of the preconditions with latest socio economical formation that is founded on status of strength of inventions and discoveries, energy sources and raw material availability. The rule of regulating authority is must to retain the functioning of prevailed social system as a precondition. The nature of such authority might vary according to the prevailed socio economic formation (leader, king and government).

e) It is inevitable to maintain and regulate some policy and principles for the regulation of the social system and its working. It is to be looked after by regulating body (government). The activities and dealing should be free from differentiations. It should be impartial. Everyone should have opportunity to make his living without prejudice and partiality etc.

We discussed the vitality of the compliance of the preconditions. It is a fact that such a critical compliance is to be done by men only. 
We are also aware that a man is with innumerable characteristics. Some of the characteristics are supportive and favourable to the demand of above compliance of preconditions. Many characteristics are very harmful to the above compliance. Our basic, vital and inevitable need for the compliance of preconditions remains at the mercy of a man (leader) or a ruler (king) or some elected team of men (government). But they are ultimately human being and all are with a set of both the characteristics. One will agree that it is uncertain which characteristic (supportive or harmful) they might expose on an event that warrants a compliance of preconditions during their working. It is controlled and regulated by many parameters. Presence of surplus population and resultant stress and strain is one of the influencing parameters on this process of selection of characteristic while acting upon time and situation by man. Ultimately, the dependency of compliance of the preconditions on human characteristics and presence of supportive as well as harmful characteristics in man constitutes a basic weakness and resultant flow in human society.

As discussed above, "flows in human society and weakness in characteristics of man" is one of the vital causes that are responsible for the subject social issues. Above subject matter is very wide; however, we shall strictly adhere to our concern only and terminate our discussion here.

\section{Difference in socio-economic formations}

The process of social development is based on inventions and discoveries, intellectual working, keeping record of memory, knowledge transfer, resources of raw material, provision for additional energy source and on other prime constituents. The pattern of social development is perpetual and slow enough. However, it always added to its progressing rate. It is because the valuable capital of past experience and revealed knowledge used to become a helpful and favourable platform to invent and discover new things. The accumulated knowledge and experience helped us revolutionarily to analyze our difficulties and challenges more classically as well as systematically to find out the remedies for the same. This status provided lucrative support to explore facts of nature and science in further depth and width.

It seems that the progress and development remained in acceleration during last one hundred years. If we plot a path of social development of a popular nation or habitation at one place on earth, we might learn that it is uniformly progressive leaving some irregular spots on time line. These irregularities might have been caused by some major upheavals due to natural calamities and outside disturbances. However, overlooking such irregularities, the path of social development remained smooth and progressive. But, it uniformly got augmented with higher rate in development process.

Every small segment of the path represents a prevailing socio economic formation at the time. However, the status of socio economic formations at both the ends of a segment of the path of social progress is always at marginal difference. If we study the status of socio economic formations at both the far ends of a group of consecutively linked segments, the difference between the two statuses at the two ends will apparently be a large one.

A habitation using wooden spear and sharp stone as weapons, caves and bush of entangle as shelter and knowledge of producing and controlling fire etc is at one socio economic formation level. If we examine the status at the same place there, after few thousand years or more, we might find men inhabiting there in a habitation using cottage or hut for shelter, horses, hogs and cows as pet animals, primitive farming system, bow-arrow and sling as weapon with use of a metal and other crude facilities, accessories and conveniences for transport-storage etc. There is a large difference between above two socio economic formations. However, the path of progress from one status to second status on time line of few thousand years or more is constituted of small group of segments, each with marginal progress. It is difficult to ascertain and distinguish such difference for a small segment on time line. But, if such marginal differences get integrated, the difference in social progress between two different socio economic formations emerges apparently.

We all are aware that the social progresses of various habitations at different places of earth were not uniform. There were and there are innumerable habitations on earth with different socio economic formations. Even today, we find majority nations with different socio economic formations. When two nations are at substantially large difference between their socio economic formations, any transaction between two nations (habitations) is one of the prime causes of the above discussed social issues in present human society. It is told in our history that great migrations in mass from one place to other place on earth caused mixing of two cultures. But, it is no less important to analyze the consequences of mixing of two habitations with a large difference between their socio economic formations. 
Migration of European people to America is the best example where socio economic formation of natives and that of people of Europe were at very large difference. At the same time the migrating people were from Europe continent where all the nations were not at same socio economic formations. However, reader should note that it was a migration and mixing. But, dealing with and establishing exchanges between two nations at a large difference in their socio economic formations are also a very sensitive process. This process must be analyzed by economists, because it has a grass root influence and connectivity with the subject social issues that we discuss in this article. Even today, we find different socio economic formation in city and that of in village in the same nation and people complains that city breaks the villages.

\section{Rights and freedom without competency}

I make two statements here.

$>\quad$ One statement is "Natural wild life never gives any right to any living creature".

$>\quad$ Second one is "Natural wild life gives unlimited rights to the entire world of living creatures provided each right is to be enjoyed at its (the creature's) risk and to be enjoyed on its abilities only".

Unfortunately, when we developed a social system of our own, some rights are conferred to all man irrespective of or without verification and confirmation.....

$>\quad$ of his competency and credibility for the same.

$>\quad$ by an audit to ascertain his capacity to share in supporting the social system he lives in.

$>\quad$ of his activities and their consequential influence on the social system.

$>\quad$ of record of his past history of his deeds and evaluation if the deeds were helpful and supportive to the present social system he lives in.

When the society was ruled by royals, kings and sword bearers, the socio economic formation of the society was presenting use of horse and bullock for farming, transporting and for travelling etc. There were no paver/rcc roads across the kingdoms. Wooden ships were with sail and oar. When we invented steam engine, electric power production and crude oil processing and use of its products, it resulted into a revolutionary development in social system. The latest social development on this line introduced many social institutions, production industries, complex network of transport as well as communication and various infrastructures for multipurpose etc.

The demand of coordination, regularization and uninterrupted functioning of above discussed social system warranted for a suitable ruling policy and method to ensure the smooth performance of social systems developed as above. This demanded to dissolve old system of ruling by sword and to extinct it to bring a fresh ruling system. The fresh system had to be introduced as an inevitable option but not as a wilful development. It is because method of ruling by some typical (royal) people with sword created frequent frictions with productive people as well as with the people with vested interests in new system. The working of productive people with the support of latest inventions and discoveries to return with high productivity frequently got hindered by old ruling system controlled by sword owners. If the working of productive people is held up, the breach of preconditions will ensure that proportionate strength of population will surely get destroyed, because it could crop up only on the foundation of higher productivity of the new socio economic formation and that of the working people.

Orthodox systems of sword ruling were wiped out progressively to replace with democratic rule. History confirms that this transformation was not a rapid change. Mankind passed through many perils before they established democracy. Perhaps, (it is my view and presumption) our forefathers were tiered with the dictatorship of sword owner and they were thirsty for the freedom in new system. They made constitution of ruling a nation that assured some rights on one qualification only and that qualification is "He is conferred with some rights only because he is born and alive in the society".

When the above concept of freedom and rights were being designed by the philosopher of the time, they would never have thought of its consequences in the future social system with different socio economic formation. The society developed with high population growth as well as with industries and infrastructures. The development made the social system a complex net work system. This was a latest socio economic formation of the society. However, the above rights are still conferred on all the people just living in the society. The rights have prevailed as per pattern designed before hundreds of years. The people in the prevailing socio economic formation inhale through social systems and institutions only. The performance of the sys- 
tems and institutions are founded on economics. If the people enjoy scheduled rights and freedom without above mentioned verification, the performance of the systems and institutions will naturally go inefficient as well as it will contract some irregularities.

Here I put a small discussion on one point to highlight the sense of my saying.

A person who has no knowledge about social science, economics and history of world casts his vote to elect a person who is going to be one of the participants ruling the whole nation. On other side, right to become one of the candidates to contest an election never verifies real competency of a candidate who is likely to handle most sensitive and influencing office to rule the nation after his election.

We all are aware that all men are with different abilities. Various media have some rights and freedom. We are aware that major part of population might be successfully influenced through the media. It is also a fact that it is the same population that is going to cast the vote to elect a ruling team. There is no effective remedy if the media influences and diverts the attention as per casted schedule.

I should remind to the reader that neither I am against nor in favour of these rights as far as my subject matter is concerned here. Here it is not my intention to evaluate if such rights should or should not be conferred, but I want to point out that such rights are also among the parameters of influence on the social issues.

This ultimately leads the society to the social issues we discuss in this article.

\section{Some biological characteristics of man and weaknesses in social system}

I enlist some varieties of characteristics like wit and wisdom, vision, flexible and compromising nature, ego, positive/negative attitude, will power, practical approach, emotional sustainability, moral and generosity, idiotic, selfishness, devotional approach, retaliatory feelings, crookedness, honesty and other many characteristics. There are still innumerable characteristics, but I have listed few of them above. We know all are linked with human beings and one or more of the above characteristics influence our actions and reactions while dealing with other people as well as with systems and institutions of our society as well as with nature even.

Do these characteristics are possessed by men only or they might be possessed by other creatures also? It is a question where I still do not have satisfactory reply in my mind. I believe, even if all the characteristics are with other living creatures, the subject characteristics could not find an opportunity and a way for external exhibition or application on outside world. It is because the wild life system does not create any such environment and opportunities where applicability of subject characteristics might be realized.

For example, a zebra will never find a lion to accept a bribe to divert his (lion's) attack only on wild beast and other animals. Unfortunately, our social system has such weaknesses that permit an excess to the above characteristics to come out in the form of actions and reactions by a man while dealing with outside world. A lion, zebra or a hyena will never find an occasion to show their dishonesty to outside world because they are in wild life system, but a man does find plenty occasions for the same in social system. The presence of above discussed characteristics in men with some weaknesses in our social system and availability of suitable environment as well as opportunities for their application on outside world are also responsible parameters for the social issues that we discuss in this article.

\section{Conclusion}

Man is an intellectual creature but it is beyond our perception why only man is intelligent. However, the gain and fruits of his intellectual efforts have boosted (supplemented) his natural abilities in folds. He found possibility to manage provisions for making living with the help of above boosted ability by invading natural resources more vigorously. However, it could be realized only if there are more working hands (llabor power) to produce and commission devices on natural resources based on inventions and discoveries. This accommodated surplus population partly creating llabor power. The set up compelled man to constitute a system that was other than wild life system i. e. Social system. But, there were untold, unwritten preconditions to be complied for the smooth performing of the social system.

The above social system created an environment inside it that gave an access to some such human characteristics that were otherwise in dormant condition in man. The evolved social system is silent about issue of surplus population. There were uneven developments in social system at different places. There were seven prime causes as discussed above that ultimately resulted into frequent and repeated breach of preconditions. 
Ultimately the repeated and frequent breach of preconditions decayed the social system giving bad impact on the smooth functioning of the social net work. The resultant development in social system reflected with the present social issues.

\section{References}

1. Bark Oscar, Theodore, Jr. and Blake, Nelson Manfred (1952). Since 1900 a history of the United States in our Times, Third Edition. New York.

2. Benjamin P. Thomas (1952). Biography of Abraham Lincoln. Southern Illinois Iniversity Press, USA.

3. Churchill, Winston S. (1964). The Second World War II. Pegasaurus Books Ltd., Arundel, United Kingdom.

4. Kennedy Hickman (Updated March 16, 2016). World War II: Marshal Georgy Zhukov. Retrieved from https://www.thoughtco.com/g00/world-war-ii-marshal-georgy-zhukov-2360175?i10c.referrer=https\% 3A\%2F\%2Fwww.google.com.ua\%2F.

5. Keynes, John Maynard (1936). The General Theory of Employment, Interest, and Money. Palgrave Macmillan.

6. Marco Polo, Hugh Murray (1845). Travels of Marco Polo. Oliver \& Boyd, Edinburg, UK. Menger, Carl (2007). Principles of Economics. Ludwig von Mises Institute, Auburn, USA. 